\title{
A Study of Cultural Empathy in Foreign Language Teaching from the Perspective of Cross-cultural Communication
}

\author{
Yunhong Jiang \\ Zhejiang Ocean University, Zhoushan, China \\ Jin Wang \\ Zhejiang Ocean University, Zhoushan, China
}

\begin{abstract}
Cultural empathy is the central part in the whole system of cross-cultural communication. Meanwhile, cross-cultural communicative ability is extremely important in foreign language teaching. It plays a crucial role in multiple ways. This paper explores the relationship between the cultural empathy and cross-cultural communicative ability, aiming to build an effective foreign language training model to improve students' skills in cross-cultural communication. Through two investigations into cultural empathy and cross-cultural communicative ability obtained by sixty undergraduates from the English department at Zhejiang Ocean University, it further proposes that there is a positive correlation of the ability of cultural empathy with the cross-cultural communicative ability. This is of great guiding significance for foreign language teaching in China.
\end{abstract}

Index Terms - cultural empathy, cross-cultural communication, foreign language teaching

\section{INTRODUCTION}

\section{A. An Overview of Cultural Empathy in Cross-cultural Communication}

With the booming development of globalization of economy and popularity of the Internet, cross-cultural communication between countries has become a common phenomenon at every moment in this world. It proposes a greater challenge to the foreign language teaching, especially the English teaching. It's known to all that English is the firstly-chosen in cross-cultural communication.

In recent years, China plays an increasingly active role in the international field which strengthens the position and influence of Chinese language and culture greatly. For the sake of introducing China better to the world, the needs of improving cross-cultural communicative competence are growing by leaps and bounds.

Cross-cultural communication between people of different cultural backgrounds always meets difficulties in many aspects. The two regions' social customs, ideals and beliefs may be completely different, and it is these different factors that create potential obstacles to cross-cultural communication. Misunderstandings between them are more likely to lead to serious cultural conflicts. In order to reduce unnecessary loss, the idea of cultural empathy is imperative.

Cultural empathy is extremely important in the system of cross-cultural communicative competence. It helps people to understand the culture from a totally different nation and try to give the suitable response to the person we are talking with. Under the function of cultural empathy, the cultural conflicts between the two communicators can be eased which is the prerequisite for effective cross-cultural communication.

\section{B. Organization of the Dissertation}

The thesis is composed of three chapters in addition to an introduction and a conclusion.

Chapter One begins with a general literature review of cultural empathy both abroad and at home, with particular attention directed to the analysis of shortcomings of cultural empathy in cross-cultural communication.

Chapter Two is the main body of the thesis. It makes an investigation into cultural empathy obtained by college English majors in China, which comes to the results, discussion and findings.

Chapter Three mainly explores some suggestions on how to improve cultural empathy in foreign language teaching in China.

The last part is the final conclusion of the paper, which gives us an overall understanding of the relationship between students' ability of cultural empathy and their cross-cultural communication competence as well as the suggestions to improve cultural empathy competence.

\section{LITERATURE REVIEW}

This chapter gives a general literature review of cultural empathy both abroad and at home, with particular attention 
directed to the analysis of shortcomings of cultural empathy in cross-cultural communication.

\section{A. Cultural Empathy Abroad}

Empathy has a wide range of application in foreign countries. Among these, the most widely used are in psychology and education, especially the language training of foreign staff involved with foreign affairs.

Matthew Schertz, in the paper Empathy Pedagogy (Matthew, 2003), applied the theory of empathy to language teaching and appealed educators to pay more attention to the teaching system which can help students cultivate the ability of empathy.

Regina W.Nganga, in the paper Impact of Cross-cultural Interaction on Counselor Trainees Development of Cultural Empathy and Intercultural Sensitivity (Regina, 2008), applied the theory of cultural empathy to counselors' training which strengthen their ability of cultural empathy and improve their cross-cultural sensitivity. It is effective to solve problems generated by people from two totally different nations.

Young, a famous scholar in the University of Oklahoma, gained a high reputation in his study concerning with the theory of cultural empathy. He put forward ten axioms which were beneficial for American immigrants to adapt to the new surroundings.

Up to now, in foreign countries, although there exist plenty of suggestions of this theory, there is no complete learning system for students to master the ability of cultural empathy and to put it into the actual use.

\section{B. Cultural Empathy at Home}

In ancient China, although without an explicit concept of "empathy", there were a number of statements similar to "empathy" in nature, such as "realm" "mood" etc. They all share something in common.

In recent years, more and more scholars have attached great importance to the theory of cultural empathy. It was first introduced into Chinese aesthetics by Zhu Guangqian in the 1930s. And then Zhu developed it and formed his own view about empathy by combining it with the Chinese traditional philosophy---the unity of heaven and humanity.(Liu Jie,2012)

He Ziran, in his article" Pragmatic Empathy in Daily Verbal Communication"(He Ziran, 1991) first brought the concept of empathy into the pragmatics, and he further subdivided empathy into pragmalinguistic empathy and sociopragmatic empathy in cross-cultural communication. (Liu Jie, 2012)

Gao Yongchen, in his paper" The Value and Cultivation of Cultural Empathy Competence in Cross-cultural Communication" (Gao Yongchen, 2005), carried out an in-depth analysis of the relevance between cultural empathy and cross-cultural communication, in which he put forward an idea "the unity of theory and reality". According to his opinion, the necessary way for cultural empathy was to maintain cultural diversity, equality and to firmly resist ethnocentrism, stereotypes and prejudice. (Liu Jie, 2012)

Wan Man, in his paper" An Analysis of the Phenomenon of Cultural Empathy in Cross-cultural Communication"(Wan Man, 2013), raised explicitly that cultural empathy competence was an important factor in successful cross-cultural communication. It can help us to build a good understanding of other nations' culture and shorten the psychological gap between different languages and cultures.

Nowadays, there are many research articles related with cultural empathy in China which point out the importance of cultural empathy competence to the study of cross-cultural communication. However, among these, only few articles are connected with the suggestions in foreign language teaching. There is still a vacancy in this area.

\section{Two InVESTigations into Cultural Empathy AMONG ENGlish MaJors IN China}

This chapter is the main body of the thesis. It makes two investigations into cultural empathy among English majors in China, which comes to the results discussions and findings in the theory.

\section{A. Research Methodology}

So far there are few researches conducted to explore cultural empathy in foreign language teaching especially among English majors, and this paper tries to mend the gap.

In this chapter, in order to provide a detailed statement of the research methodology, research subjects, research questions, data collection and method of data analysis are elaborated.

\section{Subjects}

Participants of this research involved undergraduates from the English Department at Zhejiang Ocean University. Altogether sixty undergraduates were randomly chosen from grade 2015, 2016 and 2017. The proportional distribution of participants from the three grades served to ensure that the result of the test could reflect cultural empathy obtained by college English majors comprehensively. Factors such as age, gender and previous educational experience etc were not taken into consideration. Table 1 shows information about the participants. 
TABLE 1

DISTRIBUTION OF PARTICIPANTS BY GRADES

\begin{tabular}{|l|l|l|}
\hline GRADE & NUMBER & Gender \\
\hline 2015 (juniors) & 20 & 17 female $/ 3$ male \\
\hline 2016 (sophomores) & 20 & 15 female $/ 5$ male \\
\hline 2017 (freshmen) & 20 & 13 female $/ 7$ male \\
\hline TOTAL & 60 & 45 female $/ 15$ male \\
\hline
\end{tabular}

\section{Research Question}

\section{Research 1}

This research is mostly based on the tests of Liu Lin (Liu Lin, 2004), which is to estimate the current situation of cultural empathy obtained by Chinese English majors.

The research is composed of two parts, twenty items for each. Questions in part one are designed to test students' performance of nonverbal behaviors such as gestures, space and time etc, while questions in part two are designed to examine their mastery of verbal behaviors such as exchange of greetings, addressing, asking for help or expressing gratitude etc in communicating with native English speakers. Each question is placed in a specific social context of daily communication. Participants who could achieve higher scores are believed to have a higher level of cultural empathy, and vice versa.

Research 2

In order to have a basic understanding of participants' cross-cultural communication competence, this paper adopts a test of Chen and Starosta, Intercultural Communication Scale (Chen and Starosta, 2000).

It is a five-point scale. $5=$ strongly agree. $4=$ agree, $3=$ uncertain. $2=$ disagree. $1=$ strongly disagree, and the scale in the essay includes thirty items, item 1 to item 8 for intercultural awareness, item 9 to item 18 for intercultural sensitivity and the rest for intercultural effectiveness. The specific information about the questionnaire is listed in the following table.

\begin{tabular}{|c|c|c|c|}
\hline & Three perspectives & Factors of each perspective & No. of the item \\
\hline \multirow[t]{11}{*}{ ICC } & \multirow[t]{2}{*}{ Intercultural awareness } & Basic factual information & 3.4 .5 .8 \\
\hline & & Deep structured cultural values & 1.2 .6 .7 \\
\hline & \multirow[t]{4}{*}{ Intercultural sensitivity } & Interaction engagement & 9.10 \\
\hline & & Interaction confidence & 13.14 \\
\hline & & Interaction enjoyment & 15.16 \\
\hline & & Interaction attentiveness & 17.18 \\
\hline & \multirow{5}{*}{ Intercultural effectiveness } & Interaction relaxation & 21.22 \\
\hline & & Interaction respect & 23.24 \\
\hline & & Message skills & 25.26 \\
\hline & & Identity maintenance & 27.28 \\
\hline & & Interaction management & 29.30 \\
\hline
\end{tabular}

\section{Data Collection}

Data were collected during a two-week period (from May. 13th to May. 27th). The researcher sent sixty sample tests via e-mail to sixty students from grade 2015, 2016 and 2017 in the English Department who had volunteered to participate in the research. All participants were asked to respond on a voluntary basis to the test and finish before the due time (May. 20th). A total of sixty replies were returned.

Method of Data Analysis

Data for the research 1 were all divided into three groups: freshmen, sophomores and juniors. The results were then classified and placed into table 2 .

In table 2, the results of the socio-cultural test have been focused on the current situation of cultural empathy obtained by the participants. The full score is 100 , with 2.5 scores for each item. The scores of the participants of different grades were classified into three categories---80-100, 60-80 and 0-60. The results of the three categories were then converted into a percentage.

Data for the research 2 were also divided into three groups: freshmen, sophomores and juniors. The results were then classified and placed into table 3 .

In table 3, the results have been focused on the cross-cultural communicative competence of the three grades. The full score of the research is 5 . The results of the three categories were converted into a percentage.

Table 4 combines the results of two researches into one graph, which mainly illustrates the relationship between cultural empathy and cross-cultural communicative competence.

\section{B. Results and Discussion}

In this part, the paper mainly describes, analyses and discusses the general situation of the two researches. 
TABLE 2.1

GENERAL ANALYSIS OF THE SCORE

\begin{tabular}{|l|l|l|l|}
\hline Total scores & 100 & Maximum & 92.5 \\
\hline Number of the participants & 60 & Minimum & 55 \\
\hline Number of test items & 40 & Mean & 67.5 \\
\hline Score of one item & 2.5 & Standard deviation(STEDV) & 1.628 \\
\hline
\end{tabular}

TABLE 2.2

SPECIFIC STATISTICS OF THE SOCIO-CULTURAL TEST(\%)

\begin{tabular}{|c|c|c|c|}
\hline $\begin{array}{ll}\text { Scores } & \text { Participants } \\
\end{array}$ & Freshmen & Sophomores & Juniors \\
\hline $80-100$ & 10 & 25 & 40 \\
\hline $60-80$ & 65 & 60 & 45 \\
\hline $0-60$ & 25 & 15 & 15 \\
\hline
\end{tabular}

Table 2.1 and Table 2.2 show us clearly the overall situation of the socio-cultural test. From the statistics in the chart, we can find out that juniors have an obvious advantage in getting the high score in this test because of many years' accumulation of English cultural knowledge. By comparison, freshmen and sophomores have a low level of relevant knowledge on cultural empathy. However, there is one thing which is much the same. A large majority of all these three groups are in the second range of the score (60-80) and the mean score is 67.5. Besides, the standard deviation in these statistics is 1.628 , which is small in the test. These two obvious features mean that there are no significant differences among the participants of all three grades in terms of their average level of cultural empathy, which can only be generalized as "mediocre". Chinese English majors' ability of cultural empathy still needs to be improved.

TABLE 3.1

DESCRIPTIVE STATISTICS FOR CROSS-CULTURAL COMMUNICATION COMPETENCE

\begin{tabular}{|l|l|l|l|l|l|}
\hline & Number & Minimum & Maximum & Mean & STEDV \\
\hline Freshmen & 20 & 1.30 & 4.23 & 3.33 & 0.84 \\
\hline Sophomores & 20 & 2.70 & 4.50 & 3.51 & 0.46 \\
\hline Juniors & 20 & 2.83 & 4.23 & 3.80 & 0.39 \\
\hline All & 60 & 1.30 & 4.50 & 3.55 & 1.27 \\
\hline
\end{tabular}

TABLE 3.2

SPECIFIC RESULTS OF THEIR CROSS-CULTURAL COMMUNICATION COMPETENCE(\%)

\begin{tabular}{|l|l|l|l|}
\hline Scores & Participants & Sophomores & Juniors \\
\hline 4-5(include 4) & 5 & 15 & 15 \\
\hline 3-4(include 3) & 70 & 70 & 75 \\
\hline 2-3(include 2) & 20 & 15 & 10 \\
\hline $1-2$ (include 1) & 5 & 0 & 0 \\
\hline $0-1$ (include 0) & 0 & 0 & 0 \\
\hline
\end{tabular}

Table 3.1 and Table 3.2 illustrate the overall situation of cross-cultural communicative competence of Chinese English majors in Zhejiang Ocean University. From the statistics in two charts, we can see clearly that juniors have a good command of cross-cultural awareness and they behave better than the other two grades in communication. The mean score of juniors among these is the highest. Besides, the standard deviation (STEDV) of three grades, respectively $0.84,0.46$ and 0.39 , which implies there is no distinctive differences among the participants of their own grades in terms of the average level in cross-cultural communication. The overall standard deviation is 1.27, higher than others, which is reasonable because of the different starting points in English learning. More importantly, looking at the statistics, we can find there is a large gap between the worst and the best in cross-cultural communication. The minimum is 1.30 , while the maximum is 4.50 . Among the whole ICC test, a large number of all three grades' participants fall into the second range of score (3-4). It indicates that the average level of cross-cultural communication competence of English majors in China is at moderate level. 
TABLE 4

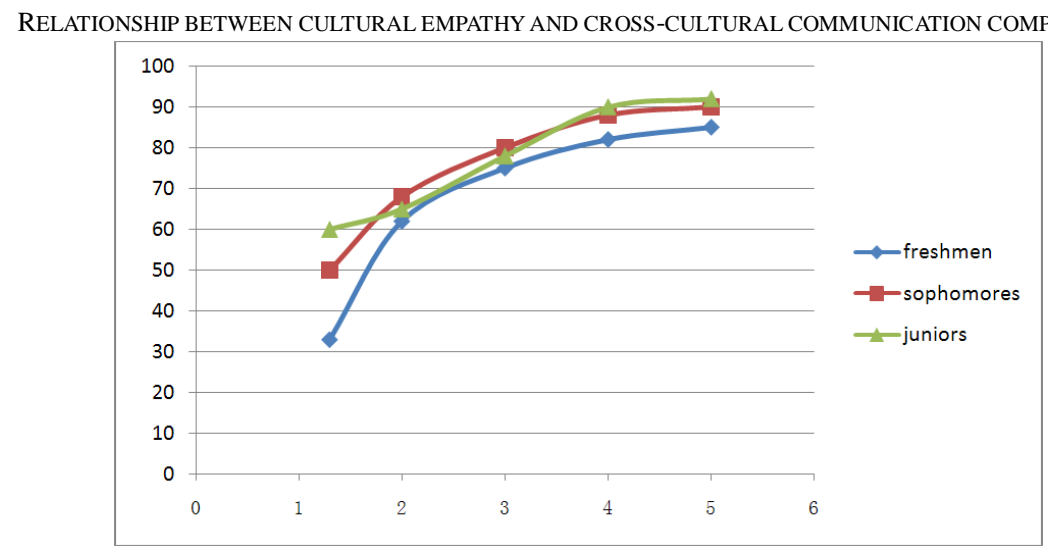

As shown in Table 4, $x$-axis represents the score in ICC while y-axis represents the score in socio-cultural test. We can easily find a positive correlation of the ability of cultural empathy with the cross-cultural communicative competence. If the English majors want to improve the ability of cultural empathy in English learning, first of all, they should pay more attention to their cultural awareness in communication.

\section{Findings}

What have been done in the previous chapter are two researches which aim to explore the relationship between the ability of cultural empathy and the cross-cultural communicative competence obtained by English majors in China. The two researches are of great practical value in that both of them provide significant suggestions for foreign language teaching in China. Based on the results and discussion above, the following conclusions can be drawn.

The ability of cultural empathy and cross-cultural communicative competence of English majors in China are generally at the moderate level (as shown in table 2 and table 3). It means that there still exist some problems while communicating with native English speakers. As we all know, compared with non-English majors, college English majors have rich experience in listening and speaking as they have received a long time of professional language training. English majors, therefore, are supposed to have better language skills and the ability of cultural empathy as well as their cross-cultural communicative competence should be better. However, the situation nowadays is obviously not. The main cause of this consequence is definitely the method of foreign language teaching in current education. We need to make great continuous efforts to achieve the goal of becoming a competent communicator.

More importantly, there is a positive correlation of the ability of cultural empathy with the cross-cultural communicative competence (as shown in table 4). It gives us the enlightenment of improving the efficiency in foreign language teaching. The ultimate goal of foreign language teaching is the development of students' cross-cultural communicative competence.(Ren Saixian, 2015) However, in today's English educational system, teachers pay more attention to vocabulary, grammar as well as the pronunciation. All of these are sure to be the essential language skills for an English learner, but these are not the most important part in English learning. The focus in foreign language teaching should be put on the cultural awareness, which we can say, the ability of cultural empathy. Therefore, it is reasonable if we claim that the cultivation of the ability of cultural empathy and the development of cross-cultural communicative competence should proceed simultaneously. The cultivation of cultural empathy deserves more attention from scholars and educators in the field of foreign language teaching.

\section{Several Suggestions for Improving Cultural Empathy in Foreign Language Teaching}

Based on the results and findings, the following suggestions can be used in foreign language teaching and learning.

\section{A. Suggestions in Class}

The main aim of learning a second language is to achieve successful communication with its native speakers through the use of cultural empathy.(Mo Liping,2011) Cultural empathy plays an extremely significant role in foreign language teaching. It is an effective method to achieve successful cross-cultural communication, which should be the focus of the second language teaching. Therefore, it's important for college English teachers to try some useful ways to cultivate students' ability of cultural empathy in college English class.

\section{To Appreciate Films}

This reform of the teaching method is welcome among students. College English teachers should take full advantage of meaningful foreign film resources so as to create an exotic atmosphere for students to learn the language. More importantly, successful films can make students have a spiritual resonance and also can reflect the variety of life and culture in foreign countries. For instance, the film The Scarlet Letter is a typical representation of mainstream American culture. When students are quietly moved by the miserable life of the main character, Hester Prynne, who fought against the puritanism and struggled for freedom and personal worth and finally gained the glory of redemption, they are, 
unconsciously, transmitting the core essence of mainstream American culture, which is characterized by some basic values such as the pursuit of individual freedom, self-reliance and an optimistic view of the future etc. Therefore, language teachers should realize that artistic forms, such as films, music, pictures etc., are more suitable for second language learners compared with volumes of textbooks on western culture as they can provide them with very vivid, specific and authentic descriptions of the target culture.

To Employ Foreign Teachers

Foreign teachers are good at the language knowledge as well as the foreign cultures. By the face to face communication, students can not only improve the ability of putting the language into actual practice, but also obtain directly the cultural knowledge of foreign countries. This kind of communication is the most straightforward and effective way in enhancing students' ability of cultural empathy and strengthening the identity of world culture.

\section{B. Suggestions after Class}

Practice is the best way to cultivate and improve students' ability of cultural empathy. It needs not only teachers' positive guidance in class but also students' positive participation in extracurricular learning. The following suggestions are helpful to improve English majors' ability of cultural empathy.

To Encourage Extensive Reading

Extensive reading is an extremely useful method while learning a second language. It not only helps learners to expand vocabulary, but also plays a crucial role in improving cultural identity and cultivating the ability of cultural empathy. To achieve this, we should encourage students to read freely and choose whatever they are interested in. By doing this, we are helping them to develop the habit of reading for enjoyment and interest and most importantly, to foster their motivation. Brown argues, "Our fervent quest in this language teaching business is, of course, to see to it that our pedagogical tools can harness the power of intrinsically motivated learners who are striving for excellence, autonomy, and self-actualization." (Brown, 2001)

After this, teachers should give their students essential guidance by providing them with a wide range of options and inspiring them to "dabble in" various fields like arts, sociology and anthropology etc. Extensive reading may not have obvious effect in a short period of time. However, all small progress will compose an integrated picture of the target culture in students' mind and thus their ability of cultural empathy can be improved.

To Choose Suitable Teaching Material Compilers

Cultural empathy plays such an indispensable role in learning English, thus when teachers select teaching materials, it is better for them to choose the materials which are full of abundant cultural background knowledge and then give tasks to students such as making conversations in the virtual cross-cultural communication situations or role playing of some famous stories. These teaching materials can help teachers and students themselves to cultivate and improve the ability of cultural empathy more effectively.

\section{CONCLUSION}

Cultural empathy has an irreplaceable position in achieving successful cross-cultural communication. Successful cross-cultural communication with the native speakers is also the final aim of second language teaching. Thus, to cultivate and improve students' ability of cultural empathy is extremely important in second language teaching.

The paper has investigated the correlation between students' ability of cultural empathy and their cross-cultural communicative competence, explored the possible ways to cultivate and improve college students' ability of cultural empathy

Through a two-week-long experiment and with the data collected from two tests, the present study has proved that there is a significantly positive correlation between students' ability of cultural empathy and their cross-cultural communicative competence. Through several useful suggestions to cultivate and improve students' ability of cultural empathy, their communicative competence can be improved correspondingly which can eventually help the development of students' second language skills and achieve the ultimate aim of learning a second language.

\section{REFERENCES}

[1] Brown, H.D. (2001). Principles of Language Learning and Teaching. Beijing: Foreign Language Teaching \& Research Press.

[2] Chen, G. M. \& Starosta, W. J. (2000). The Development and Validation of the Intercultural Sensitivity Scale. Communication Research, 3(6), 22.

[3] Gao, Y. (2005). The Value and Cultivation of Cultural Empathy Competence in Cross-cultural Communication. Liaoning: Foreign Languages and their Teaching.

[4] He, Z. (1991). Pragmatic Empathy in Daily Verbal Communication. Beijing: Foreign Language Teaching and Research Press.

[5] Liu, J. (2012). China English and Cultural Empathy. Doctoral dissertation: Shandong Normal University.

[6] Liu, L. (2004). The Development of Cross-cultural Communicative Competence in Foreign Language Teaching. Master's dissertation: Shandong Normal University

[7] Mo, L. (2011). Cultivating Students' Cultural Empathy Competence through College English Reading. Master's dissertation: Central South University.

[8] Ren, S. (2015). A Study of Intercultural Communication Competence on the Basis of Schema Theory. Master's dissertation: Agricultural University of Hebei. 
[9] Wan, M. (2013). Exploration and Elementary Analysis on Cultural Empathy in Intercultural Communication. Master's dissertation: Henan University.

Yunhong Jiang was born in Huzhou, China in 1996. She is a grade three student at Zhejiang Ocean University, China, majoring in English.

She is currently an undergraduate student at Zhejiang Ocean University, China. Her research interests include Foreign Language Teaching and Cross-cultural Research.

Jin Wang was born in Zhoushan, China. She received her Master's degree in English Language and Literature from Zhejiang University, China.

She is an associate professor in Zhejiang Ocean University, China. Her current research focuses on the "Evolution of Man-Ocean Relationship from European and American Marine Literature". 